\title{
Infrared Drying Trends Applied to Fruit
}

\author{
Jhon Wilder Zartha Sossa*, Gina Lía Orozco, Liz Mercedes García Murillo, \\ Miguel Peña Osorio and Nevardo Sánchez Suarez
}

Faculty of Agro-Industrial Engineering, Universidad Pontificia Bolivariana, Medellín, Colombia
OPEN ACCESS

Edited by:

Mohammad U. H. Joardder, Rajshahi University of Engineering \&

Technology, Bangladesh

Reviewed by:

Trude Wicklund, Norwegian University of Life

Sciences, Norway

Paulo José Do Amaral Sobral,

University of São Paulo, Brazil

*Correspondence:

Jhon Wilder Zartha Sossa jhonzarthasossa@gmail.com

Specialty section: This article was submitted to Sustainable Food Processing, a section of the journal

Frontiers in Sustainable Food Systems

Received: 07 January 2021 Accepted: 22 March 2021

Published: 14 May 2021

Citation:

Zartha Sossa JW, Orozco GL, García Murillo LM, Peña Osorio $M$ and Sánchez Suarez N (2021) Infrared Drying Trends Applied to Fruit. Front. Sustain. Food Syst. 5:650690 doi: 10.3389/fsufs.2021.650690
Aims: This article seeks to identify the main products to which drying is applied, mainly by infrared, as well as the mathematical models used to evaluate a product.

Background: The drying of agro-industrial products is a very important unitary operation to avoid post-harvest losses.

Objective: This article looks to respond to the following questions: Which raw materials are subjected to far-infrared drying? What are the mathematical models used in the application of far-infrared?

Method: To identify the most focused articles on the topic, we worked with the search equation "TITLE-ABS-KEY ('infrared drying') AND fruits AND [LIMIT-TO (SUBJAREA, 'AGRI') OR LIMIT-TO (SUBJAREA, 'ENGl')]," which was run in the Scopus database for scientific articles.

Result: After knowing the different technologies, more than 23 applications in agro-industrial products were identified. In these applications, it is observed how quality is one of the most important factors in the preservation of dehydrated products; far-infrared drying helps retain sensory quality in products such as sweet potatoes, grapes, Cordyceps militaris, and mangoes.

Conclusion: A common factor that could be found from the articles and patents was the application of this infrared drying technique in fruits and vegetables with high water content, such as kiwi, chives, and mushroom varieties. These articles and patents based their studies on optimizing the technique by varying drying times, temperatures, and pressures, even sometimes combining different drying techniques-all to preserve the organoleptic characteristics of the product, avoiding damage to thermolabile compounds and obtaining a dry food of very good quality, performance, and characteristics.

Keywords: drying, far infrared, fruits, mathematical models, agro-industrial products, unitary operation

\section{INTRODUCTION}

Drying in food and non-food agro-industrial products is a unitary operation of great importance both at a business level and at an academic and research level, since the sectors of application are quite broad, such as fruit, flowers, grains, meat, dairy, spices, and dyes. It is also an operation before many size reduction operations, increasing the useful life of the products by eliminating the highest available water content and therefore reducing costs in product transportation freight. Among various types of drying such as microwave, hot air, and some hybrid systems 
(Cuccurullo et al., 2019), drying by forced convection is the most used in this unitary operation due to the benefits of cost and time drying, but despite the abovementioned, the affectations on the nutritional and organoleptic characteristics to which the products are submitted are quite high, which have taken to the innovation in other more efficient techniques and conserve better the nutritional and organoleptic characteristics of these products. Among the most efficient techniques are freeze drying (FD), far-infrared radiation drying (FIRD), heat pump drying (HPD), hot-air drying (HAD), and hot air combined instant controlled pressure drop drying (DIC). Some of these techniques have been well-studied, but other more emerging techniques such as far-infrared drying have not had as much theory published, so this article seeks to answer the following questions: Which raw materials are subjected to far-infrared drying? What are the mathematical models used in the application of far-infrared? To answer the two questions posed, this document consists of four phases. In the first phase, a theoretical framework is presented that relates the main concepts or definitions about the unitary operation of far-infrared drying. In the second phase, the methodology is explained with emphasis on the search equation used in Scopus. In the third phase, the results are explained in terms of countries of origin of publications, type of journal, time series of the articles and topics, raw materials evaluated in the articles, and the mathematical models. The last phase contains a discussion and an analysis of patents and contributions that will give answers to the questions raised as the main axis of this article.

\section{CONCEPTUAL FRAMEWORK}

Among the most important challenges at present worldwide is the conservation of food, mainly fruits, and vegetables, which a great loss occurs in the post-harvest process. One of the alternatives that offer better results in conservation is drying, one of the oldest techniques (Cheng et al., 2019), which is one of the methods that allow the separation of water from a solid (Ocon and Tojo, 1977) and consists of reducing the moisture content to a safe level where deterioration by microbial conditions can be significantly minimized (Cheng et al., 2019).

The drying is usually by evaporation in a gaseous stream, and the most commonly used gas for the drying application is air (Zartha and Palacio, 2011). This treatment can extend the shelf life of these products with great success (Wu et al., 2019), making them more acceptable for marketing or further use (Valiente and Tlacatzin, 1991). Currently, dry products are well-received by both consumers and transporters because the dry product facilitates transport and storage reducing costs $(\mathrm{Wu}$ et al., 2019). In the last decades, different drying techniques have been developed or implemented among which are HAD, FD, microwave drying, and infrared drying (Wu et al., 2019).

HAD is a process in which food is exposed to a flow of hot air. This process has no special requirements for expensive equipment and is commonly used because of its low process costs; however, this process has low energy utilization efficiency. Hot-air-dried products can reach a shelf life of $\sim 1$ year (Wang,
2019). But the long drying time causes a significant decrease in the quality of the final product (Zhao et al., 2019).

Freeze-dried food is considered the benchmark of highquality dry products, which could preserve as much as possible several original properties of fresh materials such as appearance and nutrients (Zhao et al., 2019).

Microwave drying allows the food material to be placed in an electromagnetic field where, due to the friction and collision of the water particles, its temperature is increased and the process of water evaporation is accelerated (Wang, 2019). This method is compared to forced convection drying with hot air; microwave drying has a shorter drying time, has higher energy efficiency, and improves properties such as aroma, color, and rehydration, along with nutritional properties (Leanerts et al., 2018).

One of the drying methods that has gained great relevance in recent years at an industrial level is infrared drying, which years ago did not appear as an option for the industry, but due to the research on this type of drying that has been carried out and the advantages it has over other drying methods, it has begun to be implemented.

Infrared drying is based on electromagnetic radiation. Compared to other drying media, especially HAD, infrared produces savings in energy consumption, which is an important step toward conserving available energy sources (EL-Mesery et al., 2019). In similar conditions, infrared drying has great advantages over traditional air drying. Studies have shown that infrared has an effective moisture diffusivity and a higher thermal sensitivity than air drying (Wu et al., 2019).

In the industry, there are three types of infrared drying (far-, near-, and medium-infrared drying), of which the most emerging has been the far-infrared drying. This can be widely implemented in the food industry, as it can be used to dry a wide variety of agricultural products. This type of drying has several advantages if compared to traditional drying, ranging from efficient heating of products and excellent energy efficiency to a high quality of dry products because this type of drying does not allow the organoleptic and chemical characteristics of the products to be lost.

Several studies determined that drying of agricultural material through far-infrared is one of the most efficient, since the heating that takes place in it manages to promote the rate of dehydration of the products and also helps to improve the quality of these. This type of drying is very versatile, since it can be used alone or as a complement to other operations (Liu et al., 2019).

Infrared drying is quite practical due to its uniform heat distribution, fast drying speed, and simplicity of the equipment. Among the infrared technologies, FIRD was found to be more suitable for food processing, as most food components could absorb radioactive energy in the far-infrared region (Zhao et al., 2019).

Infrared radiation has become an alternative technique for food drying because the equipment required for this process is versatile and simple, which allows faster heating and therefore reduces drying times. Infrared drying works when the infrared radiation penetrates the material, and it is converted into heat energy and thus removes water more evenly. Infrared drying allows a more uniform distribution of heat than convection 

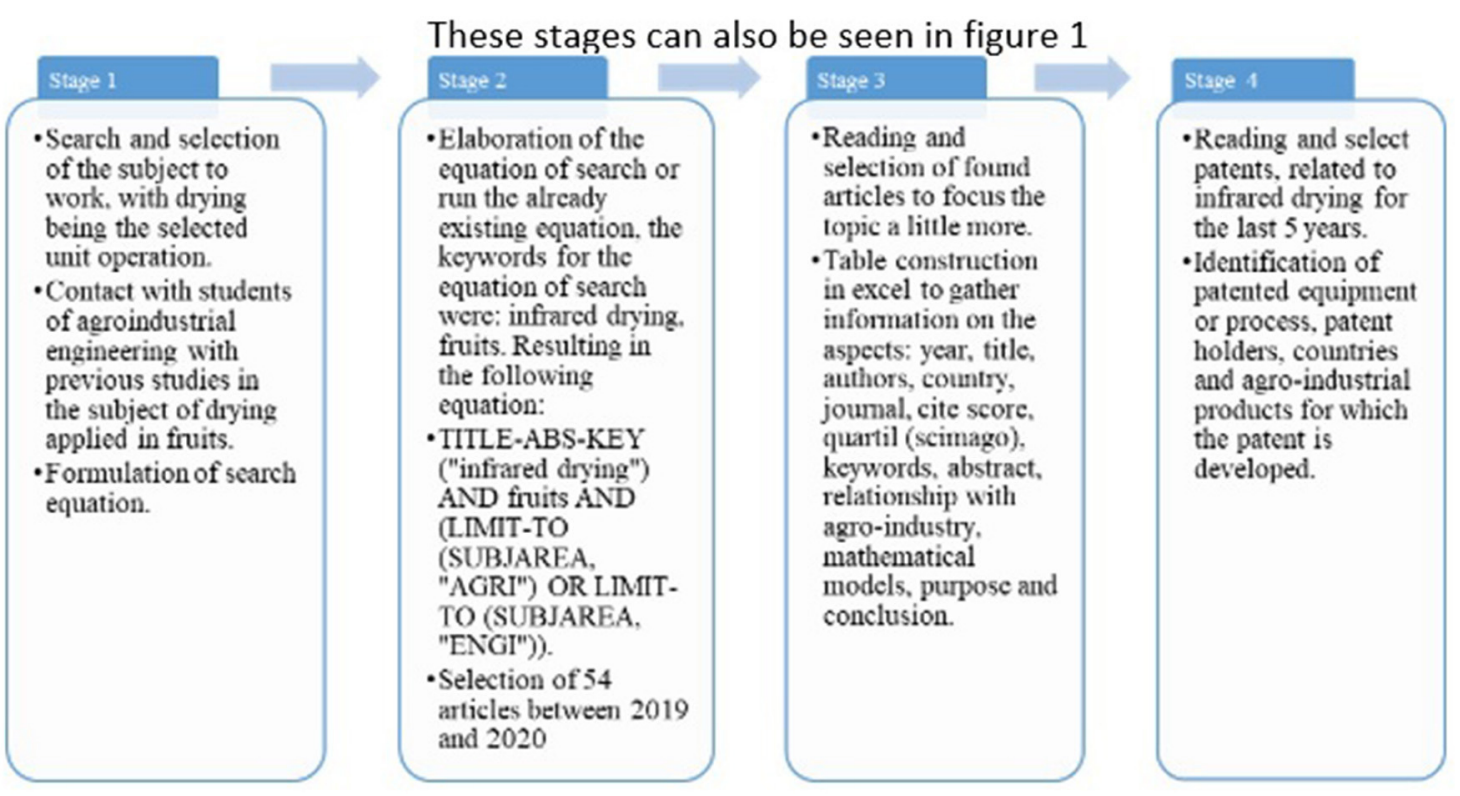

FIGURE 1 | Stages of paper creation. Source: the authors.

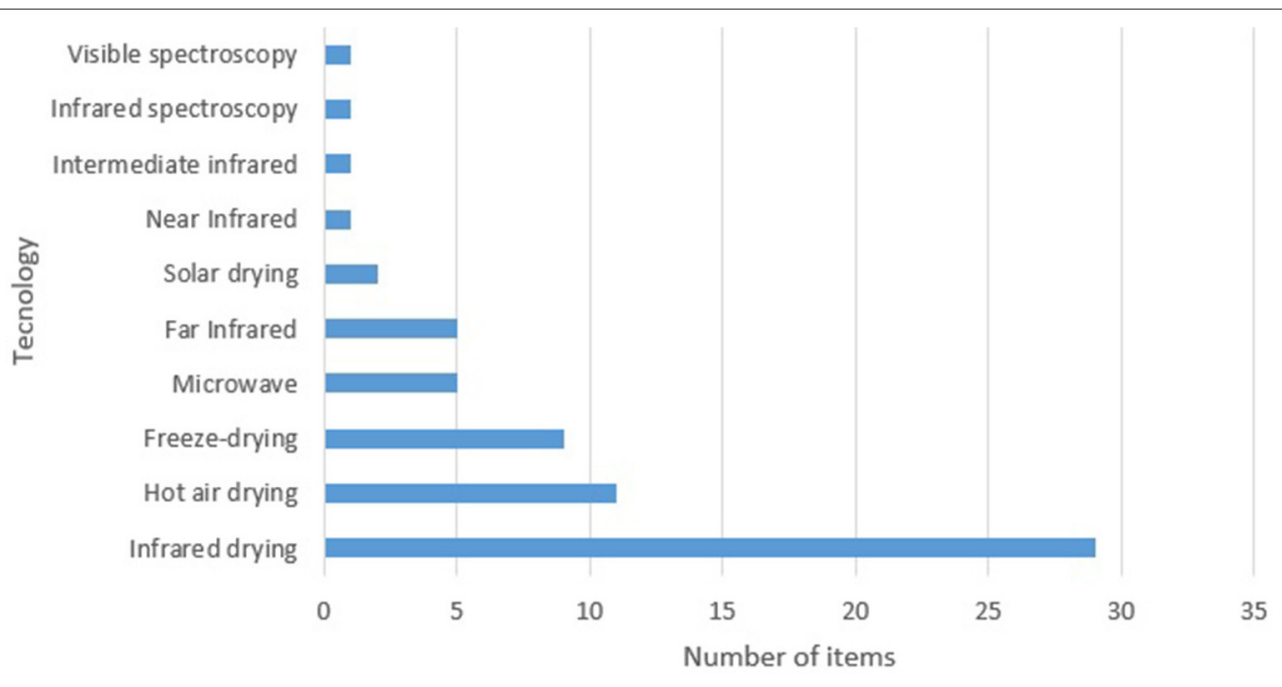

FIGURE 2 | Technologies found in the search. Source: the authors.

drying, and therefore, a higher-quality product is obtained (Rashid et al., 2019).

\section{METHODOLOGY}

To obtain good results in the reading, the work was divided into four stages as follows:

- Stage 1: Search and selection of the topic to work on. The topic of drying was chosen because it is an old method that is very useful for the industry today. Subsequently, contact was made with agro-industrial engineering students who had already made progress in drying technologies applied to fruit. The search equation with which the work was developed was obtained.

- Step 2: Elaboration of a search equation or run of the already existing equation to obtain articles

- To expand the topic, the keywords used for the equation were Infrared drying, Fruits, resulting in the following equation:

- TITLE-ABS-KEY ("infrared drying”) AND fruits AND [LIMIT-TO (SUBJAREA, “AGRI”) OR LIMIT-TO (SUBJAREA, "ENGI")]. As it was an equation previously worked with, only 54 articles were taken into account between 2019 and 2020. 


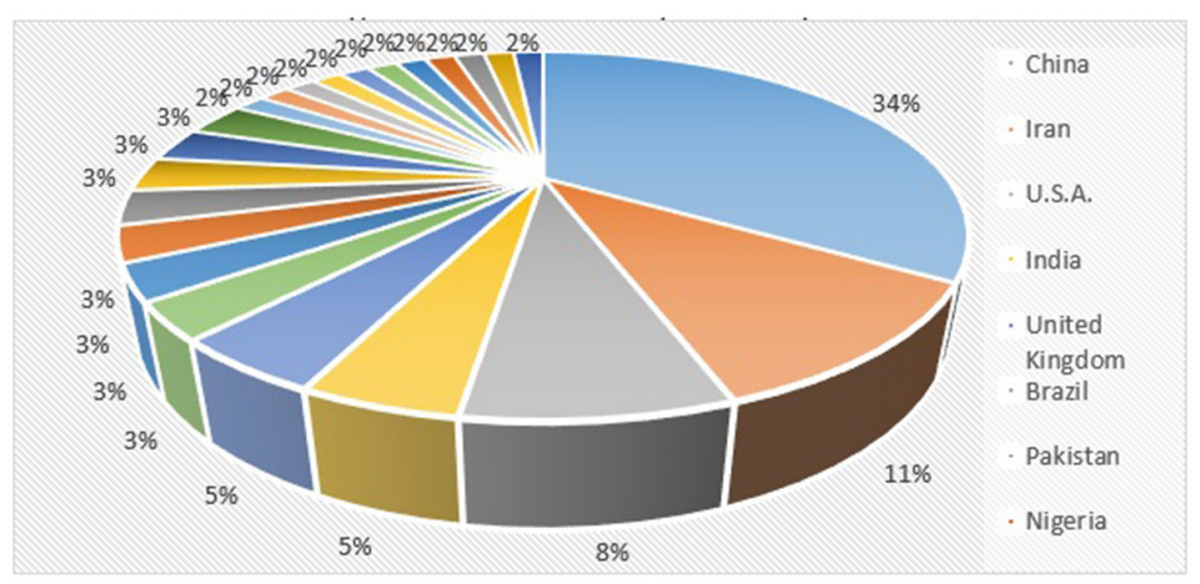

FIGURE 3 | Countries that produced publications. Source: the authors.

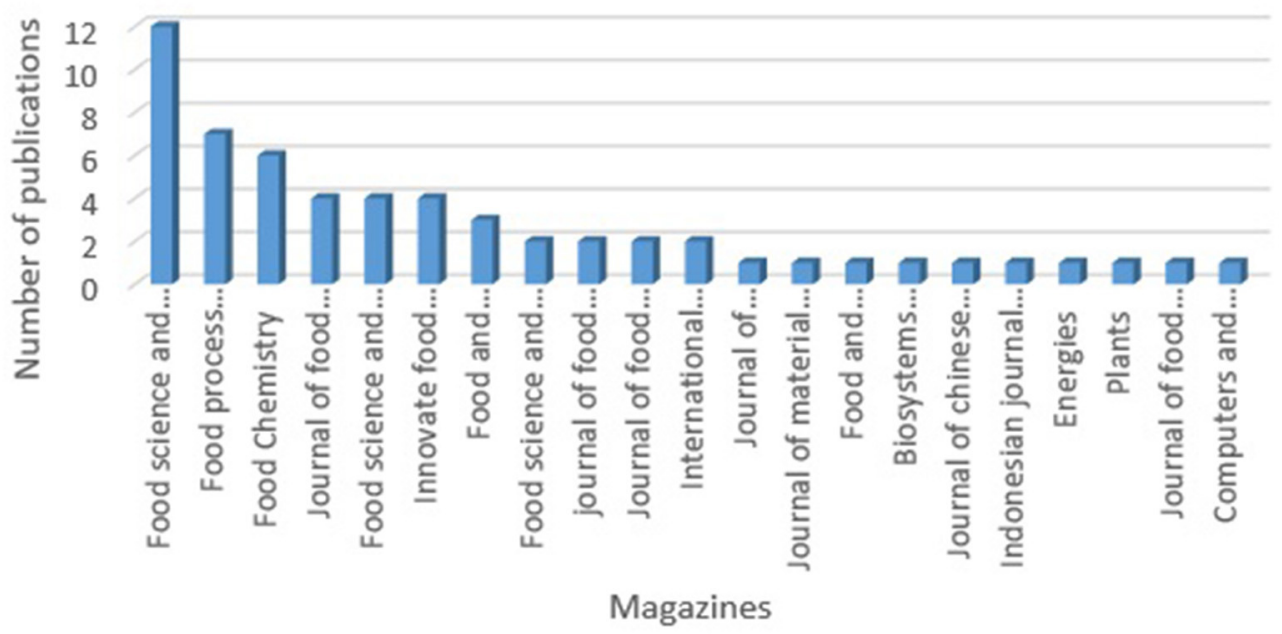

FIGURE 4 | Magazines that made the publications. Source: the authors.

- Stage 3: Reading and selection of the articles found to focus a little more on the subject. After reading the 54 articles, a format was constructed that contains the following aspects: year, title, authors, country, journal, cite score, quartile (SCImago), keywords, summary, relationship with agro-industry, mathematical model, purpose, and conclusion.

- Stage 4: patent evaluation related to the stage 2 search equation for the last 5 years, identifying patented equipment or methods, agro-industrial products, companies or patent applicants, and countries.

These stages can also be seen in Figure 1.

\section{RESULTS}

To achieve a good analysis, first, the information found in the articles was organized, and to determine better results, graphs were created representing the results obtained. The graphs were created with the information of the countries that made the publications, the magazines in charge of publishing the articles, the main keywords found in each article, the most used technologies, and the products to which they are applied in that technology. Also, to determine the level of impact of the journals in which the articles were published, with the quartile in which each journal is located, a graph was made. It should be noted that there are four quartiles (Q1, Q2, Q3, and Q4) for the most important journals, in which the journals located in Q1 are those that have the greatest impact. The results obtained can be seen in Figures 2-6 and Table 1.

In Figure 2, the characterization of the technologies related to the unitary drying operation found in the articles evaluated can be seen, which amounts to 10 technologies, in which infrared drying is identified as the technology with the highest number of articles that refer to it, being $\sim 28$ articles, while 


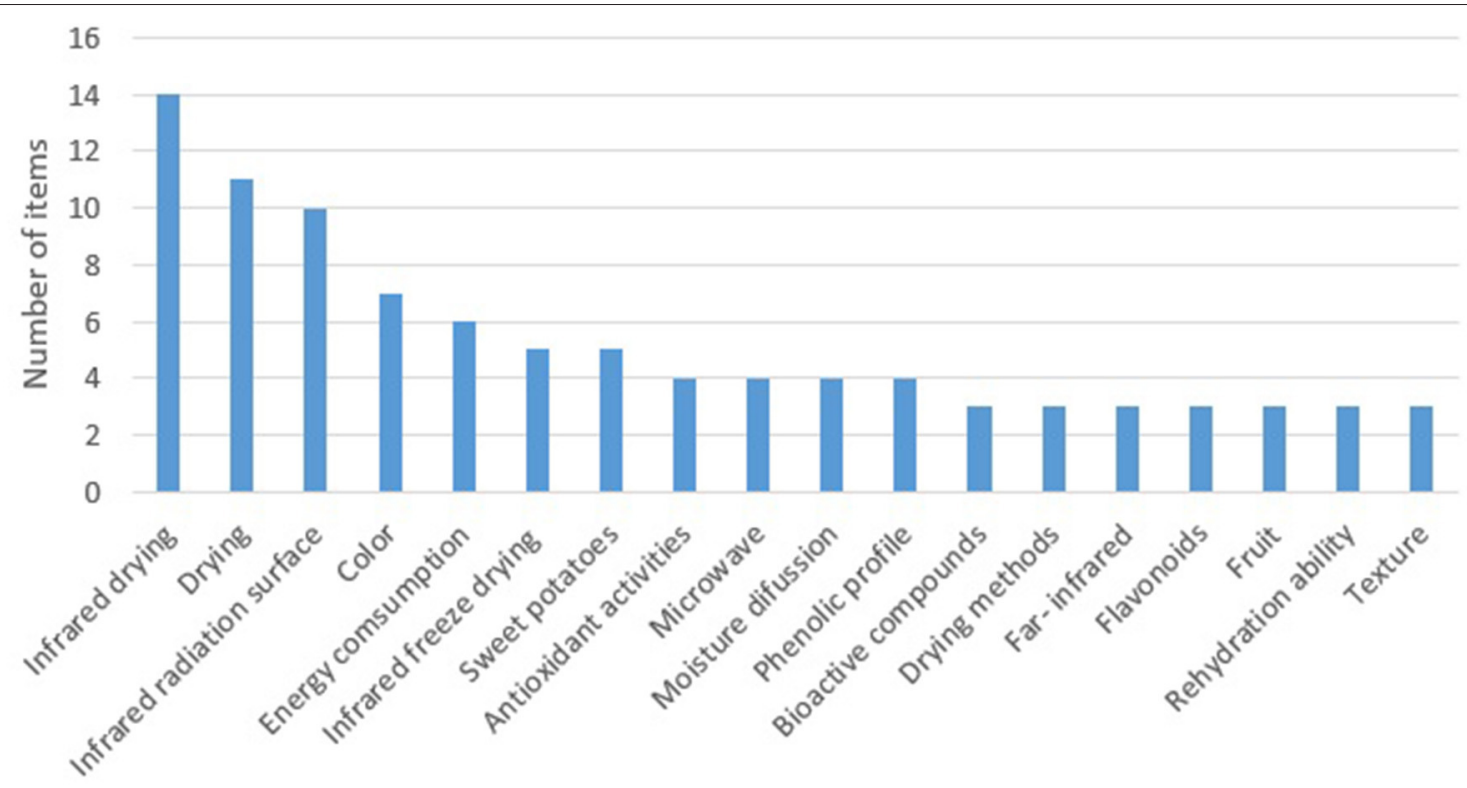

keywords

FIGURE 5 | Word most found keys. Source: the authors.

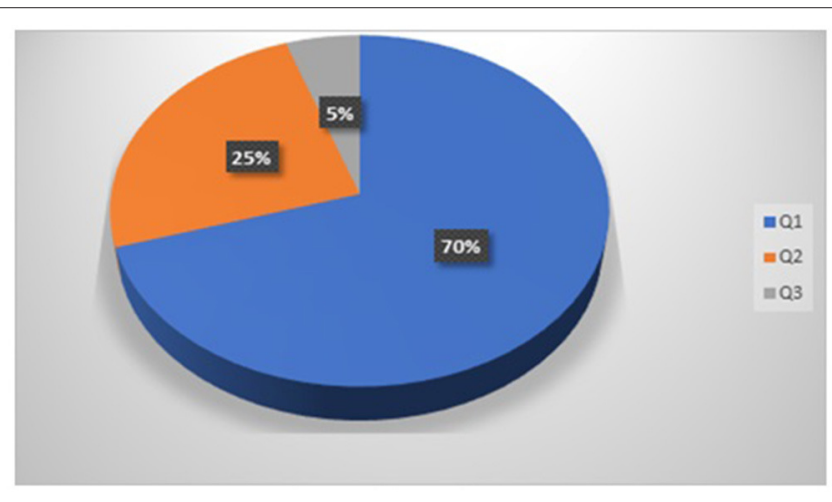

FIGURE 6 | Quartile of the location of the magazines. Source: the authors.

the technology that appears in the lowest number of articles is drying by visible spectroscopy mentioned in two articles. But in this case, although the infrared drying is the most studied, it is not emerging. There are reports of its application from more than 10 years ago, which is why it is discarded, and farinfrared drying is selected, which was studied in five articles of the year 2019 and 2020, which shows that it is an emerging technology that brings multiple positive effects in the drying of agro-industrial products, leaving it in an advantage over the other technologies.

After knowing the different technologies, the products worked in all the articles were identified, and Table $\mathbf{1}$ is created in which the author, the product that this author investigated, and the purpose of this investigation are shown. This table is made to extend a little more information about the products and the purpose of these for each author, besides that it is possible to understand more widely the discussion that is later on.

Taking into account that the drying process is a very important operation for the conservation of food and the quality of the final product, which leads to innovate in new drying processes or evaluate the different technologies that exist to determine which is the most appropriate, taking into account the type of product and the process to which it will be submitted after the drying to ensure the higher performance of the product and longer duration, that is why in Figure 3, we can see which are the countries that have most evaluated the drying technologies applied to raw materials, China being the country with the highest percentage of publications of articles with 34\%, followed by Iran, which had a participation of $11 \%$, and the United States, with $8 \%$ of publications. We can also find to Colombia with a participation of $2 \%$ and 19 other countries that made publications of the drying technologies.

Figure 4 shows a compilation of the journals publishing the articles studied, in which 21 journals are reported, among which food science and technology, food process engineering, and food chemistry present the three first places concerning a greater number of publications of articles with a percentage of publications of 11, 7, and 6, respectively.

Keywords are an important part of an article, since just by reading them, we can deduce the subject of the article as well as make it easier to find the articles in the databases. For this reason, Figure 5 shows a compilation of keywords of the articles evaluated, giving a total of 18 keywords being infrared drying, drying, and infrared radiation Surface, the frequent keywords, participating in 14,11 , and 10 articles respectively. 
TABLE 1 | Identification of products worked by each author.

\begin{tabular}{|c|c|c|}
\hline References & Product & Purpose \\
\hline Rezaei et al. (2019) & Potato slices & Measure the shrinkage of the potato slice area during the drying process \\
\hline Rashid et al. (2019) & Sweet potato slices & $\begin{array}{l}\text { The study aims to determine the drying of sweet potatoes with multi-frequency ultrasound pre-treatment (U.S.A.). } \\
\text { UU. }(20,40 \text {, and } 60 \mathrm{kHz}) \text { at three different infrared (IR) drying temperatures }\left(60,70 \text {, and } 80^{\circ} \mathrm{C}\right) \text { and evaluate the } \\
\text { phytochemical and textural effect. }\end{array}$ \\
\hline Onwude et al. (2019) & Sweet potato slices. & Determine the performance of different combined infrared (IR) and hot air strategies for sweet potatoes. \\
\hline Qu et al. (2019) & Black Tea & $\begin{array}{l}\text { Identify the types of drying for the tea leaves, which guarantee the best nutritional, organoleptic and sensory } \\
\text { characteristics of the final product }\end{array}$ \\
\hline $\begin{array}{l}\text { Khampakool et al. } \\
\text { (2019) }\end{array}$ & Banana snacks. & Preserve features, plus cost savings for processing and transforming raw materials, such as fruits. \\
\hline Lin et al. (2019) & $\begin{array}{l}\text { Mushroom slices and } \\
\text { whole mushrooms }\end{array}$ & $\begin{array}{l}\text { Investigate the impact of microwave vacuum drying (MVD) on moisture uniformity in Mushroom slices and whole } \\
\text { mushrooms (Agaricus bisporus) by hyperspectral imaging in the near-infrared (NIR) in combination with } \\
\text { multivariate analysis. }\end{array}$ \\
\hline Rojas et al. (2019) & Potato slices & $\begin{array}{l}\text { This work explored the use of ethanol and perforations individually and combined to improve both infrared drying } \\
\text { and rehydration of potato slices. }\end{array}$ \\
\hline Zhou et al. (2019) & Peaches & $\begin{array}{l}\text { To evaluate the effect of infrared dehydration as a function of diffusion humidity, when using this integrated with a } \\
\text { convective drying method }\end{array}$ \\
\hline Yao et al. (2019) & Mango slices & $\begin{array}{l}\text { Dry mango slices by } 2 \text { methods, hot air drying, and far-infrared drying, evaluating the effects on the } \\
\text { physicochemical and organoleptic characteristics of the product. }\end{array}$ \\
\hline Selvi et al. (2020) & Rose petals & $\begin{array}{l}\text { To evaluate the effects of infrared drying at different temperatures and times on rose petals, evaluating color } \\
\text { change, phenolic content, and dry area. }\end{array}$ \\
\hline Sadeghi et al. (2019) & Kiwi fruit & $\begin{array}{l}\text { To evaluate the physicochemical behavior of kiwifruit when subjected to infrared drying and to determine the } \\
\text { variables of drying. }\end{array}$ \\
\hline Ratseewo et al. (2019) & Rice varieties & To evaluate the effects of convection and far-infrared drying, in pigment rice, concerning bioactive compounds. \\
\hline Kayacan et al. (2020) & Khaki Fruit & $\begin{array}{l}\text { To evaluate the effects of } 4 \text { drying techniques (convection drying, infrared, freeze-drying, and ultrasound with } \\
\text { vacuum), against chemical compounds in khaki fruit and to determine the most efficient drying. }\end{array}$ \\
\hline Darvishi et al. (2019) & Tasty herbs & $\begin{array}{l}\text { Evaluation of the drying variables, such as wind speed, temperature, infrared power, and the relationships with } \\
\text { rehydration, color change, and energy consumption, to optimize the drying process and guarantee its quality. }\end{array}$ \\
\hline $\begin{array}{l}\text { Quispe-Fuentes et al. } \\
\text { (2020) }\end{array}$ & Machia berries & $\begin{array}{l}\text { To evaluate the effects of four drying techniques (convection drying, infrared and vacuum drying, freeze-drying, } \\
\text { and sun-drying), against the physicochemical compounds of machine-goats. }\end{array}$ \\
\hline Cheng et al. (2019) & Mango slices & $\begin{array}{l}\text { A comparison of traditional solar and tunnel drying methods was carried out, and a control sample dried using an } \\
\text { electric dryer, and it was observed that the samples dried by traditional solar drying were the ones with the } \\
\text { greatest variation. }\end{array}$ \\
\hline Wu et al. (2019) & Cordyceps militaris & $\begin{array}{l}\text { The moisture ratio was measured to determine the factor that most affects the drying kinetics and the final } \\
\text { properties of the product. }\end{array}$ \\
\hline EL-Mesery et al. (2019) & Biomass & $\begin{array}{l}\text { The total energy consumption (Et) and the specific energy consumption (SEC) were calculated to determine how } \\
\text { expensive a biomass drying process can be and to analyze which process can be more economical. }\end{array}$ \\
\hline Shchitov et al. (2019) & Animal Feed & Infrared drying for animal feed on a farm \\
\hline Gao et al. (2019) & Lemon & $\begin{array}{l}\text { The main purpose of this research was to determine the effect of various methods of dehydration on the phenolic } \\
\text { components and antioxidant activity of the lemon. }\end{array}$ \\
\hline Wang et al. (2019) & Shiitake mushrooms & $\begin{array}{l}\text { Perform comparative analyses on drying kinetics, color, rehydration ratio, polysaccharide content and composition } \\
\text { of aromatic components of shiitake mushrooms dried by hot air drying, infrared drying and microwave-assisted } \\
\text { intermittent hot air drying }\end{array}$ \\
\hline Wu et al. (2019) & Cordyceps militaris & $\begin{array}{l}\text { In this study, a new laboratory-scale apparatus was developed that uses infrared lamps to replace the electric } \\
\text { heating plate for the freeze-drying of Cordyceps militaris. }\end{array}$ \\
\hline Zhou et al. (2019) & Shiitake mushrooms & $\begin{array}{l}\text { The purpose of this study was to evaluate the effect of different drying methods on the sensory and nutritional } \\
\text { attributes of shiitake mushrooms. }\end{array}$ \\
\hline Hasan et al. (2019) & Fruits and vegetables & To apply drying technologies (infrared) on fruits and vegetables to extend the shelf life and means of conservation. \\
\hline Cuccurullo et al. (2019) & Apple slices & Compare the performance and color change in the product, using different drying methods and temperatures \\
\hline Zeng et al. (2019) & Kiwi slices & To analyze the behavior and changes in characteristics of kiwifruit slices using the far-infrared radiation technique. \\
\hline $\begin{array}{l}\text { Khaing Hnin et al. } \\
\text { (2019) }\end{array}$ & $\begin{array}{l}\text { Yogurt that melts pink } \\
\text { flavored }\end{array}$ & Compare two different drying techniques to determine which has better effects on the product \\
\hline Safarov et al. (2019) & Rosehips & Establish the appropriate drying parameters to be applied to the product to have the expected results. \\
\hline Sadeghi et al. (2019) & Kiwi slices & $\begin{array}{l}\text { To evaluate different effects such as coarseness, the distance between samples, cut thickness, etc. When } \\
\text { evaluating moisture diffusion and drying speed of kiwifruit pieces }\end{array}$ \\
\hline Sadeghi et al. (2019) & $\begin{array}{l}\text { Evaluation of different } \\
\text { mathematical models }\end{array}$ & Determine the drying curves between a large number of mathematical models and artificial neural networks \\
\hline
\end{tabular}


TABLE 1 | Continued

\begin{tabular}{|c|c|c|}
\hline References & Product & Purpose \\
\hline Hnin et al. (2019) & $\begin{array}{l}\text { Agricultural products } \\
\text { for healthy snacks }\end{array}$ & $\begin{array}{l}\text { Compare three drying methods to establish their efficiency and which both contribute to the organoleptic } \\
\text { characteristics of different agricultural products as well as measuring water activity, expansion ratio (ER), and bulk } \\
\text { density, as well as other aspects. }\end{array}$ \\
\hline Nalawade et al. (2019) & Mint leaves & $\begin{array}{l}\text { The effect of four dried types on the quality of the product was evaluated in terms of chlorophyll, total carotenoids, } \\
\text { essential oil yield and composition, color, browning index, and rehydration ratio. }\end{array}$ \\
\hline Wang et al. (2019) & Chives slices & $\begin{array}{l}\text { The effects of vacuum, ethanol pre-treatment, and infrared hot air-drying methods on the characteristics and } \\
\text { quality of spring onion slices were examined. }\end{array}$ \\
\hline Liu et al. (2019) & Kiwi slices & $\begin{array}{l}\text { This study was conducted to observe the effect of ultrasound on moisture migration while performing the } \\
\text { far-infrared drying process. }\end{array}$ \\
\hline Illa et al. (2019) & Bacterial cellulose & $\begin{array}{l}\text { The effect of drying on the physicochemical, morphological, and structural properties of bacterial cellulose } \\
\text { produced by Fourier transform infrared spectroscopy was systematically studied. }\end{array}$ \\
\hline $\begin{array}{l}\text { Vega-Gálvez et al. } \\
\text { (2019) }\end{array}$ & Chilean papaya & $\begin{array}{l}\text { The effect of } 5 \text { different types of drying on bioactive compounds and biological activity of Chilean papaya was } \\
\text { evaluated. }\end{array}$ \\
\hline Carvalho et al. (2019) & Macadamia nuts & $\begin{array}{l}\text { Evaluate the oxidative stability of intact macadamia nuts using near-infrared spectroscopy, oven-dried for } 4 \text { days } \\
\text { at } 30^{\circ} \mathrm{C}, 2 \text { days at } 40^{\circ} \mathrm{C} \text {, and } 1 \text { day at } 60^{\circ} \mathrm{C} \text { to achieve a grain moisture content of } 1.5 \% \text {. }\end{array}$ \\
\hline Nogueira et al. (2019) & $\begin{array}{l}\text { Acerola (Malpighia } \\
\text { emarginata D.C.) }\end{array}$ & Use the residues of the acerola, drying them, to be able to take advantage of its bioactive compounds. \\
\hline Onwude et al. (2019) & Sweet potatoes & Improve the quality of the dry product, by intermittent infrared and convection (IIRCD) \\
\hline Fu et al. (2019) & Grape Seeds & $\begin{array}{l}\text { To determine the effects of infrared radiation combined with the heating on the grape seeds and the quality of the } \\
\text { oil. }\end{array}$ \\
\hline Yu et al. (2019) & Asparagus stalks & To evaluate the properties of asparagus stems after different drying methods. \\
\hline $\begin{array}{l}\text { Borda-Yepes et al. } \\
\text { (2019) }\end{array}$ & Blueberry Leaves & To evaluate the effects of infrared drying and microwave drying on the polyphenol content of blueberry leaves. \\
\hline Yan et al. (2019) & Bitter Gourd & Evaluate different drying methods on the quality of the bitter gourd. \\
\hline
\end{tabular}

Source: the authors.

In Figure 6, we can see the classification of the quartile of the magazines that published the articles of the drying technologies. This allows us to evaluate the importance of the magazines within their area, which is divided into four quartiles, classified from highest impact to lowest impact (Cheng et al., 2019), with those in Q1 having the greatest impact on the scientific community. In this case, we have 70\% of journals in Q1, 25\% in Q2, and finally $5 \%$ in Q3.

\section{DISCUSSION}

Journals that publish scholarly articles have a different focus each, although they may be in the same area each focusing on something different, some may generalize the topic while others zoom in and reduce the information further, making it more accurate and focused on some specific topics. In the research, in general, it was found that all the magazines talk, mostly, about topics focused on food, technologies, innovation, engineering, and research.

The journal in which more publications were found in the "food science and technology" followed by the "food process engineering," both journals focused on a food field, one in science and technology and the other in engineering processes. These journals seek to publish progress on these issues, and to determine the progress, the best option is to compare it with what already exists or with other techniques to determine which is the most effective, and this is as several authors express it, as Carvalho et al. (2019), Wang (2019); and Fu et al. (2019), among others who made comparisons between different methods of drying and comparison between the product by applying the treatment and without applying it.

This is what these journals are looking for-to publish the improvements that have been found by different researchers worldwide, to improve access to information, and to generate benefits for the readers who are carrying out their research. The journals also have an impact level that is determined by the quartile SCImago in which it is located, the quartile what it looks for is to locate the publication in a journal according to its level of importance and impact, achieving this way that the publications are ordered so that the readers can facilitate their search of information (COLCIENCIAS, 2018), taking into account the previous thing and that the quartiles are Q1, Q2, Q3, and Q4, where Q1 is composed of the journals with the greatest impact, the current review is based on 70\% of publications in Q1 journals, which suggests that the articles used for the study have a great impact among readers of research-related topics.

The research focused on the reading of publications on drying especially with the infrared technique, that is why in the search of keywords exposed by the authors of the publications, the main ones that are found are "infrared drying," "drying," "infrared radiation surface," and some of the different products that are applied to the drying. The keywords are important because they allow the reader to identify which is the central topic of the article you are reading. This is why if the research was based on the search for infrared drying information, the most keywords found 
were related to these topics. Some of the authors who mention the most repeated keywords in the articles are Rashid et al. (2019), Daniel and Onwude (2019), Khampakool et al. (2019), and Borda-Yepes et al. (2019), among others.

They in their publications gave reason for the advances they have achieved with this drying technique compared to other techniques and with the improvement in the retention of the nutritional compounds of the products. Based on the above, it was possible to identify more easily the issues related to the research.

\section{Products or Found in the Reading}

The drying of raw materials is a unitary operation of great importance in the handling of raw materials and their use, as can be seen in Figure 7. The range of products evaluated with the drying technologies is quite wide at 30 raw materials for different agro-industries, the shitake fungi being the most studied, followed by the kiwi. Most of these raw materials underwent evolution to determine the most efficient drying technology in terms of conservation of physicochemical and organoleptic properties. The objective of the investigations consulted, as it has already been expressed, is to achieve an improvement in a certain process. For the present case, it is to identify the improvements in the process of drying fruits and some vegetables using infrared, and for that, it was necessary to measure the differences that were achieved, comparing the process of drying with another type of drying, for example, HAD, lyophilization, and spray drying, among others.

To observe the improvements, the results were analyzed by the different authors applying some mathematical models. Rezaei et al. (2019) used linear and algorithmic models to determine the shrinkage or reduction of the area of potato slices, managing to optimize the adjustment of the power of the microwave with which the infrared used for drying is applied. Borda-Yepes et al. (2019) used the drying curves to determine the moisture present in a product, which was dried by infrared and by microwaves, concluding that microwave drying preserves better qualities than infrared does. Wang (2019) compared HAD, infrared drying, and microwave drying and determined which of these was more appropriate and presented better conditions for processing shiitake mushrooms, determining that microwave drying considerably reduced drying time and higher polysaccharide content compared to the other methods. Besides Zhao et al. (2019) made a sensory, texture, and nutritional evaluation of shiitake mushrooms dried by four different methods, cold drying, far-infrared drying, heat pump drying, and $\mathrm{HAD}$, determining that far-infrared drying was the one that obtained better overall quality in shiitake mushrooms.

The products to which the different treatments are applied are varied, but they have something in common, that is, the search for the different changes and improvements in the conservation of the same ones. Some mushrooms are worked by Wang (2019), Lin et al. (2019), Wu and Zhang (2019), Wu et al. (2019), and Zhao et al. (2019). Potatoes and sweet potatoes are among the most investigated products found, investigated by Rezaei et al. (2019), Rashid et al. (2019), Daniel and Onwude (2019), Rojas et al. (2019), and Onwude et al. (2019). All the authors investigated the products to adjust the drying processes and seeking to obtain a high-quality product while reducing costs. The authors also express that with research and making the respective adjustments to the equipment and the process, infrared drying can become a very useful technique for drying.

The agro-industrial products that are subjected to drying are very diverse, but more often, we are starting to work with exotic fruits, which have a lot of potential in the agro-industry because of the high nutritional component they possess, also for these times where the tendency is to rescue or discover other foods that reinforce diets, healthy, and without the addition of chemicals, giving other alternatives for consumption in places where there is still food insecurity.

\section{Mathematical Models}

We were able to identify the most important and most implemented mathematical models (which are repeated more in the literature) in far-infrared drying, which are shown in Table 2, in this same table, you can see the implementation given by the different authors to each of the models. Only three mathematical models were extracted, and these are repeated in two or more articles, and because in others they only used some formulas for simple calculations, so importance was given to the most advanced.

Many of the articles are comparisons between various drying techniques to determine the most efficient, but others focus on the description of mathematical models. To standardize the drying processes by determining the optimal variables to carry out the drying operation efficiently, in these, drying curves, optimal temperatures of drying, wind speed, the distance of the product to the infrared radiation, and the power of the same are determined. The models are very varied, as can be seen in Table 2; this depends on the object of study and the results expected in each product.

The study also identified a statistical model, analysis of variance (ANOVA), which is implemented in infrared drying to determine the most significant processes of the same but also implemented to determine the most optimal variables to perform the drying process, variables such as humidity, temperature, time, etc. Cheng et al. (2019) used this model to compare two drying methods, one with far-infrared and the other without far-infrared, giving favorable results for the method that implemented far-infrared.

Most of the mathematical and statistical models used in the articles have the purpose of predicting or determining an important variable in the drying process, either the drying speed, drying temperature, or the amount of humidity that a product to be dried may present. In some cases, these mathematical models are implemented with the purpose of being able to calibrate the equipment in the most optimal way to obtain the best results for its later analysis (Cheng et al., 2019). These are fundamental in this process, since they are in charge of determining if the product to which this process was carried out lost all the humidity that it presented when initiating the process of drying (Rojas et al., 2019). These are fundamental, since when making them, it is possible to be avoided that a finished product is commercialized with humidity, which can generate losses either 


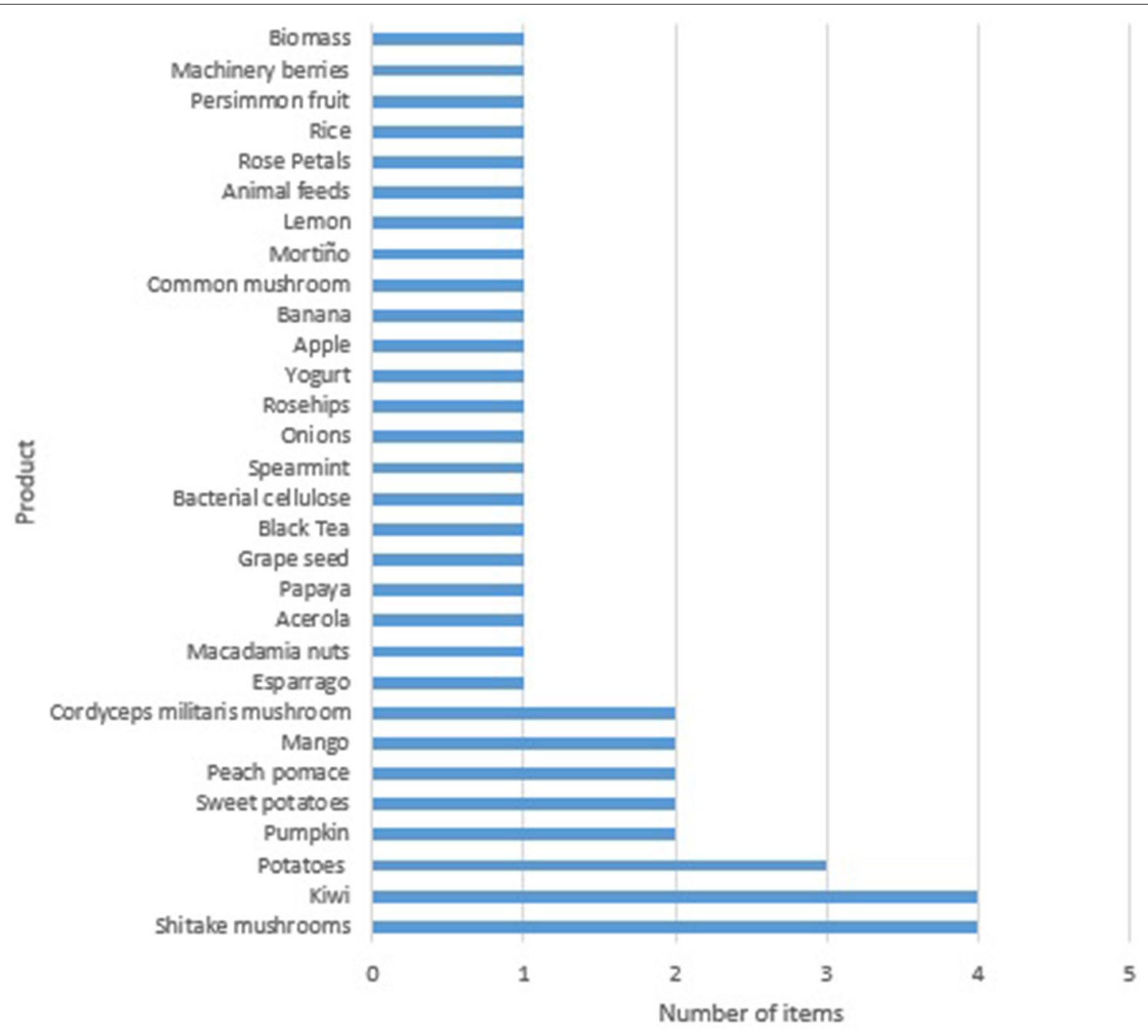

FIGURE 7 | Products or MPs investigated. Source: the authors.

because it does not fulfill the wished characteristics or by the growth of microorganisms or fungi in the product due to the humidity content. Although drying many mathematical models can be taken into account in this article, they look for the same thing as those exposed and that is to determine a specific variable in the drying process, whether it is infrared drying, spray drying, or FD.

The applications of far-infrared drying found vary greatly, such as studying the effects on products, as in the case of pumpkin (Yan et al., 2019) or asparagus stems (Yu et al., 2019). Another application found was the study of properties on products, such as the determination of polyphenols in blueberry leaves (BordaYepes et al., 2019) or the study of the oxidative stability of the macadamia nut (Carvalho et al., 2019). Infrared drying is one of the most versatile that can be found in the industry. It can be coupled with other processes in a very easy way, not to mention that this is one of the most economical for its low consumption energy and the high quality that it provides the final product (Liu et al., 2019).

\section{Effects on Quality Through Infrared Drying}

Quality is one of the most important factors in the preservation of dehydrated products. Far-infrared drying helps retain sensory quality in products such as sweet potatoes, grapes, Cordyceps militaris, and mangoes, as explained by different authors (Fu et al., 2019; Onwude et al., 2019; Wu and Zhang, 2019; Yao et al., 2019), where they identified that the taste and smell of the product remained very similar to fresh samples of it. Another important component to verify the conservation of quality is the color that the product or food takes after the drying process. Some authors identified that the color is quite preserved in the product, which is very important in its marketing (Cheng et al., 2019; Nalawade et al., 2019; Wu et al., 2019; Zhao et al., 2019). The infrared drying method also provides a faster operating time compared to other drying methods while maintaining compositional and sensory characteristics at high levels (Ebrahim et al., 2019; Hasan et al., 2019; Qu et al., 2019; Zeng et al., 2019). Table 3 shows in detail the contribution of the authors concerning quality. 
TABLE 2 | Identification of mathematical models worked by the different authors.

\begin{tabular}{ll}
\hline Mathematical model & Implementation \\
\hline Algorithmic linear models. & $Y=\beta_{0}+\beta_{1} X_{1}+\beta_{2} X_{2}+\ldots+\beta_{i} X_{i}$ \\
& Where $Y$ is the dependent variable, $\beta_{0}$ is the intercept, $\beta_{i}$ is the slope for $X_{i}$ and $X$ is the independent variable. \\
& This model is implemented in far-infrared drying to determine a variable of the drying or a variable of the product, \\
& an example of this is what is done in the article (Rezaei et al., 2019) in which they use this method to predict the \\
percentage of moisture that has the product to be dried, in the same article this model is again used to calibrate & \\
the power of the drying equipment.
\end{tabular}

Drying curves

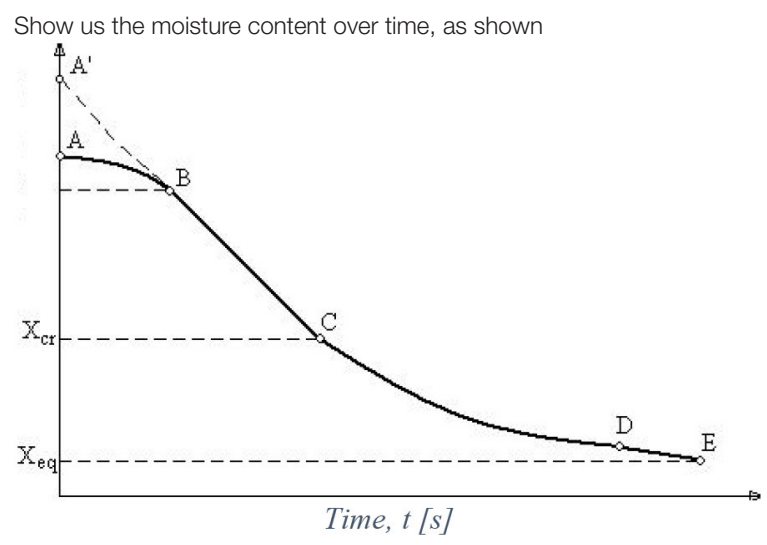

Time, $t[s]$

A-B: initial drying period

B-C: constant drying rate period

C-D: drying speed drop period

D-E: critical drying period

If we talk about drying, we must also talk about drying curves, which are implemented to determine if the product or food to which the drying is being done is the right one, the amount of water required was eliminated since it is well-known that if after drying the product still contains water, it can develop microorganisms which affect the physical or organoleptic properties of the product, generating losses because of were commonly found in the literature review.

The model Page: $\left.\mathrm{MR}(\mathrm{t})=e^{(}-k t n\right)$

This model is implemented to set the drying data, data coming from the drying speed or other process constants

Source: the authors.

\section{Complementary Analysis From Patents}

To analyze the usefulness and implementation of the far-infrared drying system, the patents applied for and obtained in the last years were reviewed. For this purpose, the search equation "TITLE-ABS-KEY ('infrared drying') AND fruits AND [LIMITTO (SUBJAREA, 'AGRI') OR LIMIT-TO (SUBJAREA, 'ENGI')]” was run again in Scopus, obtaining more than 600 patents in all years. To reduce the search and make it more current, we chose to work only with the last 5 years in which 146 patents were found. When performing the analysis, we found that only 10 patents use far-infrared drying applied to fruits or agro-industrial products; the rest of the patents, several have nothing to do with far-infrared drying or with fruits, others include drying methods or equipment but none is far-infrared, and there is another group that uses far-infrared drying but not applied to fruits. After analyzing the 10 patents directly related to the topic, a consolidation was made with the information as shown below:

\section{Products to Be Dried}

Products vary slightly between the different patents, but generally, it was found that systems, equipment, or methods are used for a wide range of products because changing products only requires extending the time or intensity of the infrared rays. Among the products mentioned in the patents are sweet potatoes (Kiburo, 2019), fruits and vegetables in general (Kyoon, 2017; Musco et al., 2017; Kisaburo, 2018; Wicherski, 2018), nuts (Takamasa, 2017; Wicherski, 2018), grains (Jiménez and Gopi, 2018), plant leaves for making tea (Pan and McHugh, 2017), and agro-industrial products (Bing et al., 2017; Altser, 2018). The products worked on in the patents are very similar to those who worked on in the articles, and they also seek to conserve, extend the life, and preserve the properties of the articles.

\section{Equipment, Systems, or Methods}

In general, they are constituted by cameras or equipment in which the main drying is made with the application of rays of distant infrared. With these systems, one looks to improve the yield of the production, diminishing the costs of the process and simultaneously looking for better control in the process as far as the times and temperatures, which are very important variables at the time of working with fruits and vegetables in general due to which the physical-chemical properties can be deteriorated. 
TABLE 3 | Effects on the quality of infrared drying.

\begin{tabular}{|c|c|c|}
\hline Authors & Product & Quality \\
\hline Cheng et al. (2019) & Mango & $\begin{array}{l}\text { EI VIS-NIR spectrum is well adapted to measure fruit maturity and the NIR spectrum has a great } \\
\text { potential to investigate and control dryer performance. The latter demonstrated that the tunnel dryer } \\
\text { provides a much smoother and more uniform drying process compared to the traditional dryer. In } \\
\text { contrast, samples from the traditional dryer showed chemical changes/decomposition. }\end{array}$ \\
\hline Wu et al. (2019) & Cordyceps militaris & $\begin{array}{l}\text { Higher drying temperature favors the storage of dry products. Drying at } 40^{\circ} \mathrm{C} \text { is beneficial for color } \\
\text { retention and volatile compounds. For non-volatile flavor, the relatively high drying temperature was more } \\
\text { effective in reducing bitterness and aftertaste. }\end{array}$ \\
\hline Zhao et al. (2019) & Shitake mushrooms & $\begin{array}{l}\text { The shitake mushroom showed better appearance, less shrinkage, less hardness, higher rehydration } \\
\text { rate }(7.55) \text {, higher protein retention }(2.30 \mathrm{mg} / \mathrm{g}) \text {, higher polysaccharide retention, shorter drying time } \\
\text { ( } 66.5 \% \text { less), and overall better quality in far-infrared drying compared to freeze-drying, hot air heat pump } \\
\text { drying and instantaneously controlled pressure drop. }\end{array}$ \\
\hline Qu et al. (2019) & Black Tea Leaves & $\begin{array}{l}\text { The infrared drying compared to the hot air drying, improves the quality of the Tea specifically the } \\
\text { compounds volatiles and the taste. Obtaining total sensory scores of } 85.2 \text { which is higher than the } 83.1 \\
\text { obtained in the hot air drying. }\end{array}$ \\
\hline Yao et al. (2019) & Mango & $\begin{array}{l}\text { Infrared drying maintains the quality of the mango very similar to fresh mango samples, in aspects } \\
\text { related to color, flavor, aroma, and nutritional compounds. }\end{array}$ \\
\hline Sadeghi et al. (2019) & Kiwi fruit & $\begin{array}{l}\text { Infrared is a suitable heating method for the production of high-quality dry food at low cost to reduce } \\
\text { drying time. Rehydration is one of the quality indices used by the food industries. }\end{array}$ \\
\hline Wu and Zhang (2019) & Cordyceps militaris & $\begin{array}{l}\text { IRFD could reduce } 7.21-17.78 \% \text { of the drying time and } 11.88-18.37 \% \text { of the energy consumption at a } \\
\text { constant drying temperature compared to TFD without compromising the quality of the dry product. }\end{array}$ \\
\hline Hasan et al. (2019) & Fruits and vegetables & $\begin{array}{l}\text { The infrared drying provided a higher drying speed, lower shrinkage percentage, and also decreased } \\
\text { color deterioration (an important aspect to verify the quality of the drying). }\end{array}$ \\
\hline Zeng et al. (2019) & Kiwi fruit & $\begin{array}{l}\text { An increase in FIR temperature decreased } L^{*} \text {, but increased to * dry kiwifruit values and affected total } \\
\text { phenolic content, total flavonoid content, and vitamin } \mathrm{C} \text { content. }\end{array}$ \\
\hline Nalawade et al. (2019) & Food in general & $\begin{array}{l}\text { It maintains the sensory quality of food, reduces processing time so it can be explored as an alternative } \\
\text { to drying heat-sensitive products such as spearmint. }\end{array}$ \\
\hline Onwude et al. (2019) & Sweet potatoes & $\begin{array}{l}\text { Infrared drying is superior to conventional drying techniques in terms of drying time, energy } \\
\text { consumption, and the sensory and nutritional quality of the dryer. }\end{array}$ \\
\hline Fu et al. (2019) & Grapes & $\begin{array}{l}\text { Infrared drying helps to maintain food quality without degrading it and at the same time helps with the } \\
\text { inactivation of aerobic and mold yeast bacteria. }\end{array}$ \\
\hline
\end{tabular}

\section{Countries}

Countries do not vary much from those publishing the articles, and among them, we find Japan and the United States with three patents each and Korea, Poland, China, and the United Kingdom with one patent each.

\section{Companies or Applicants}

Companies, if they are more diversified, as only one entity found, has two patents, and is the U.S. Secretary of Agriculture. The other companies belong to the agro-industrial sector, energy, technology, and among others, the companies are PAPEL TACHIBANA DESGASTE KK, SHANGHAI RELI TECH GROUP CO. LTD., HOKUETSU DENKEN KK, WICHERSKI ENERGY, TEMPONOVO LEASING LTD., RISE PRODUCTS INC., AND HOKUETSU DENKEN CO.

This paper makes contributions that allow complementing and updating information about drying operation from the point of view of teaching in faculties of agro-industry, agribusiness, food and related engineering, in books as Ocon and Tojo (1977), Treybal (1986), Valiente and Tlacatzin (1991), Warren Mcabe (1991), and Geankoplis (2006). Theoretical elements are provided on the types of drying, the operation of some equipment, as well as a mathematical model to solve drying problems under constant conditions and continuous drying; however, these texts do not delve into the infrared drying of agroindustrial products, including the book on technology entitled Unitary Operations in Food Engineering by Ibarz and Barbosa (2005), which also does not mention aspects of infrared drying of food.

This paper also provides important information on the characteristics based on organoleptic quality, obtained by agroindustrial products that are subjected to infrared drying, where it is explained how these products retain their qualities of flavor, aroma, and color, information that is presented by different authors who present recent studies on the subject, such as Cheng et al. (2019), Wu et al. (2019), and Yao et al. (2019), among others, the way providing theoretical components based on the different practical applications useful for food conservation.

Additionally, this paper compiles information that had not been found in other reviewed papers. Although there is another review on drying (Hasan et al., 2019), none covers the subject so broadly, so this paper sought to create a much broader vision of the subject, including its definition, areas of application, results obtained from the different studies carried out, and something very important, which are the patents that have been obtained on equipment focused on infrared drying, which is why the paper becomes a great review tool for subsequent research in the area. 


\section{CONCLUSIONS}

It was possible to identify drying as one of the most useful techniques for food preservation and that infrared drying was entering as a promising emerging technique for this treatment, and effectively, as expressed by the different authors, it was possible to identify what the drying process consisted of and how infrared is a technique that is well-implemented and with the respective adjustments can be effective in preserving fruit or food.

Drying is an operation that not only allows us to remove moisture from a product but also helps to make studies on the properties of these easier. In addition to combining new techniques such as far-infrared radiation, traditional drying methods better preserved the characteristics of these products.

Far-infrared drying aims to be one of the most widely used drying techniques in the future due to the benefits it brings such as low energy consumption and other features such as sensory quality, rehydration ability, and high nutrient retention that it provides to the final product.

Over time, the most effective way of preserving food has been studied, starting with sun drying and evolving into much more sophisticated techniques where the control of multiple variables is fundamental to guarantee the integral preservation of products-both their physicochemical and their organoleptic properties. This review of these technologies allows us to identify far-infrared drying as a very efficient drying technique that allows the dehydration of agro-industrial products with less physicalchemical impact.

A common factor that could be found from the articles was the application of this infrared drying technique in fruits and vegetables with high water content, such as kiwi, chives, and mushroom varieties. These articles based their studies on optimizing the technique by varying drying times, temperatures, pressures, even sometimes combining

\section{REFERENCES}

Altser, H. R. (2018). Method of Production of Dry Products of Animal and Vegetable Origin United Kingdom Patent No. WO2018124911.

Bing, S., Juncheng, Q., and Yu, Z. (2017). Container Drying System and Drying Method that Emples Radiación Infrarrojos Lejos. China Patent No. WO2017181922.

Borda-Yepes, V. H., Chejne, F., Daza-Olivella, L. V., Alzate-Arbelaez, A. F., Rojano, B. A., and Raghavan, V. G. (2019). Effect of microwave and infrared drying over polyphenol content in Vaccinium meridionale (Swartz) dry leaves. J. Food Process Eng. 42:12939. doi: 10.1111/jfpe.12939

Carvalho, L. C., Leite, M. L., Morais, C. L. M., Lima, K. M. G., and Teixeira, G. H. (2019). Non-destructive assessment of the oxidative stability of intact macadamia nuts during the drying process by near-infrared spectroscopy. Food Sci. Technol. 103, 101-107. doi: 10.1016/j.lwt.2018.12.056

Cheng, W., Sørensen, K. M., Mongi, R. J., Ndabikunze, B. K., Chove, B. E., Sun, D.-W., et al. (2019). A comparative study of mango solar drying methods by visible and near-infrared spectroscopy coupled with ANOVA-simultaneous component analysis (ASCA). LWT. 2019:112. doi: 10.1016/j.lwt.2019.05.112

COLCIENCIAS (2018). Model of Classification of Scientific Magazines. Bogota: Publindex.

Cuccurullo, G., Metallo, A., Corona, O., and Cinquanta, L. (2019). Comparing different processing methods in apple slice drying. Part 1. Performance of different drying techniques-all to preserve the organoleptic characteristics of the product, avoiding damage to thermolabile compounds and obtaining a dry food of very good quality, performance, and characteristics.

Drying is an operation that has accompanied human beings from their beginnings. This one is in almost all the industries, from the nourishing industry, for the elaboration of kinds of milk, in the dust, coffee, sugar, or dry fruits, until the no nourishing industry like the chemistry, this is an operation like the man has come evolving with time, obtaining several advances, like more optimal equipment to dry certain products, with more capacity and less power expense or equipment that maintains all the characteristics of the product that one of the most important factors today at the time of carrying out the drying process.

The articles presented in the paper are recent in 2019 and 2020 and give a basis for two things: a comparison is being made between traditional drying techniques, exposed by different authors, and a modern technique, exposed by the authors of recent studies on drying, and in turn that the information found, mainly on quality, is very current, being important to bring the technique to the practical exercise.

\section{AUTHOR CONTRIBUTIONS}

All authors listed have made a substantial, direct and intellectual contribution to the work, and approved it for publication.

\section{ACKNOWLEDGMENTS}

To the Universidad Pontificia Bolivariana for providing us with the necessary databases to search for information. To colleagues Alexander Arrieta, Elder Tejada, and Laura Vanegas for working on the first part of the research. microwave, hot air, and hybrid methods at constant temperatures. Biosyst. Eng 188, 331-344. doi: 10.1016/j.biosystemseng.2019.10.021

Daniel, I., and Onwude, N. H. (2019). The effectiveness of combined infrared and hot-air drying strategies for sweet potato. J. Food Eng. 241, 75-87. doi: 10.1016/j.jfoodeng.2018.08.008

Darvishi, H., Farhudi, Z., and Behroozi-Khazaei, N. (2019). Multi-objective optimization of savory leaves drying in continuous infrared hot air dryer by response surface methodology and desirability function. Food Sci. Technol. 168:105112. doi: 10.1016/j.compag.2019.105112

Ebrahim, S., Ali Haghighi, A., and Kamyar, M. (2019). Optimization and quality evaluation of infrared-dried kiwifruit slices. Food Sci. Nutr. 8, 720-734. doi: $10.1002 /$ fsn 3.1253

EL-Mesery, H. S., Abomohra, A. E-F., Kang, C-U., Cheon, J-K., Basak, B., and Jeon, B-H. (2019). Evaluation of infrared radiation combined with hot air convection for energy-efficient drying of biomass. Energies 12:2818. doi: 10.3390/en12142818

Fu, R., Xiao, Z., Pan, Z., and Wang, H. (2019). Effects of infrared radiation combined with the heating on grape seeds and oil quality. Food Sci. Technol. 25, 160-170. doi: 10.1177/1082013218808902

Gao, W., Zhang, Q., Wang, R., Li, G., Zhang, J., Shan, Y., Ding, S. (2019). Impact of dehydration methods on the phenolic compounds and antioxidant activity of lemon slices. J. Chin. Inst. Food Sci. Technol. 60, 1269-1275. doi: 10.1016/j.lwt.2014.09.001 
Geankoplis, C. J. (2006). Transport Processes and Principles of Separation Processes. México: CECSA.

Hasan, M. U., Malik, A. U., Sajid Ali, A. I., Munir, A., Amjad, W., and Anwar, R. (2019). Modern drying techniques in fruits and vegetables to overcome postharvest losses: a review. J. Food Processing Preserv. 43:e14280. doi: $10.1111 /$ jfpp. 14280

Hnin, K., Zhang, M., and Li, W. B. (2019). Comparison of quality aspects and energy consumption of restructured taro and potato chips under thre drying methods. Food Sci. Nutr. 42:e13249.

Ibarz, A., and Barbosa, G. V. (2005). Operaciones Unitarias en la Ingenieria de Alimentos. España: Ediciones Mundi-prensa.

Illa, M. P., Sharma, C. S., and Khandelwal, M. (2019). Tuning the physiochemical properties of bacterial cellulose: effect of drying conditions. J. Mater. Sci. 54, 12024-12035. doi: 10.1007/s10853-019-03737-9

Jiménez, B., and Gopi, A. G. (2018). Methods to Converter Organic Subproducts in Food Ingredients. United States Patent No. US20180295864.

Kayacan, S., Karasu, S., Kübra Akman, P., Goktas, H., Doymaz, I., and Sagdic, O. (2020). Effect of different drying methods on total bioactive compounds, phenolic profile, in vitro bio accessibility of phenolic, and HMF formation of persimmon. Food Sci. Technol. 118:108830. doi: 10.1016/j.lwt.2019.108830

Khaing Hnin, K., Zhang, M., Devahastin, S., and Wang, B. (2019). Influence of novel infrared freeze drying of rose flavored yogurt melts on their physicochemical properties, bioactive compounds, and energy consumption. Food Bioprocess Technol. 12, 2062-2073. doi: 10.1007/s11947-019-02368-x

Khampakool, A., Soisungwan, S., and Park, S. H. (2019). The potential application of infrared assisted freeze-drying (IRAFD) for banana snacks: drying kinetics, energy consumption, and texture. Food Sci. Technol. 99, 355-363. doi: 10.1016/j.lwt.2018.09.081

Kiburo, E. (2019). The Far-Infrared Drying Device. Japón Patente $n{ }^{\circ}$ J. P.3P.2200023220002

Kisaburo, E. (2018). Farm Infrared Drying Apparatus. Japan Patent No. JP2018071836.

Kyoon, J. T. (2017). Type Of Aircraft Transporter Of Infringement Rays Continuous Drying Suitable. Corea Patent No. WO2017195922.

Leanerts, S., Borght, M. V. D., Callens, A., and Van Campenhout, L. (2018). Suitability of microwave drying for mealworms (Tenebrio Molitor) as an alternative to freeze-drying: impact on nutritional quality and color. Food Chem. 254, 129-136. doi: 10.1016/j.foodchem.2018.02.006

Lin, X., Xu, J-L., and Sun, D-W. (2019). Investigation of moisture content uniformity of microwave-vacuum dried mushroom (Agaricus bisporus) by NIR hyperspectral imaging. Food Sci. Technol. 109, 108-117. doi: 10.1016/j.lwt.2019.03.034

Liu, Y., Zeng, Y., Hu, R., and Sun, X. (2019). Effect of contact ultrasonic power on moisture migration during far-infrared radiation drying of kiwifruit. Food Bioprocess Technol. 13, 430-441. doi: 10.1007/s11947-019-02401-z

Musco, J., McHugh, T. H., and Pan, Z. (2017). Olive Leaf Powder. United States Patent No. US9724376.

Nalawade, S. A., Ghiwari, G. K., and Hebbar, H. U. (2019). Process efficiency of electromagnetic radiation (EMR)-assisted hybrid drying in spearmint (Mentha spicata L.). J. Food Processing Preserv. 43, 1-10. doi: 10.1111/jfpp. 14190

Nogueira, G. D. R., Silva, P. B., Duarte, C. R., and Barrozo, M. A. S. (2019). Analysis of a hybrid packed bed dryer assisted by infrared radiation for processing acerola (Malpighia emarginata D.C.) residue. Food Bioproducts Process. 114, 235-244. doi: 10.1016/j.fbp.2019.01.007

Ocon, G. J., and Tojo, B. G. (1977). Chemical Engineering Problems. Cadiz: Aguilar S.A.

Onwude, D., Hashim, N., Abdan, K., Janius, R., and Chen, G. (2019). Experimental studies and mathematical simulation of intermittent infrared and convective drying of sweet potato (Ipomoea batatas L.). Food Bioproducts Process. 114, 163-174. doi: 10.1016/j.fbp.2018.12.006

Pan, Z., and McHugh, T. H. (2017). Infrared Bleaching, Infrared Whitening, and Infrared Drying Technologies for Food Processing. United States Patent No US9723851.

Qu, F., Zhu, X., Ai, Z., Ai, Y., Qiu, F., Ni., D. (2019). Effect of different drying methods on the sensory quality and chemical components of black tea. Food Sci. Technol. 99, 112-118. doi: 10.1016/j.lwt.2018.09.036
Quispe-Fuentes, I., Vega-Ga 'lvez, A., Aranda, M., Poblete, J., Pasten, A., Bilbao-Sainz, C., et al. (2020). Effects of drying processes on composition, microstructure, and health aspects from maqui berries. J. Food Sci. Technol. 57, 2241-2250. doi: 10.1007/s13197-020-04260-5

Rashid, M. T., Ma, H., Jatoi, M. A., Wali, A., El-Mesery, H. S., Ali, Z., et al. (2019). Effect of infrared drying with multifrequency ultrasound pretreatments on the stability of phytochemical properties, antioxidant potential, and textural quality of dried sweet potatoes. J. Food Biochem. 43:e12809. doi: 10.1111/jfbc. 12809

Ratseewo, J., Meeso, N., and Siriamornpun, S. (2019). Changes in amino acids and bioactive compounds of pigmented rice as affected by far-infrared radiation and hot air drying. Food Chem. 306:125644. doi: 10.1016/j.foodchem.2019.125644

Rezaei, S., Behroozi-Khazaei, N., and Darvishi, H. (2019). Microwave power adjusting during potato slice drying process using machine vision (infrared). Comput. Electron. Agri. 160, 40-50. doi: 10.1016/j.compag.2019.03.013

Rojas, M. L., Silveira, I., and Augusto, P. E. (2019). Improving the infrared drying and rehydration of potato slices using simple approaches: perforations and ethanol. J. Food Process Eng. 42:e13089. doi: 10.1111/jfpe.13089

Sadeghi, E., Haghighi Asl, A., and Movagharnejad, K. (2019). Mathematical modeling of infrared-dried kiwifruit slices under natural and forced convection. Food Sci. Nutr. 7, 3589-3606. doi: 10.1002/fsn3.1212

Safarov, J. E., Sultanova, S. A., Dadayev, G. T., and Samandarov, D. I. (2019). Method for drying fruits of rose hips. Int. J. Innov. Technol. Explor. Eng. 9 , 3765-3768. doi: 10.35940/ijitee.A4716.119119

Selvi, K. Ç., Kabutey, A., Kag` an Gürdil, G. A., Herak, D., Kurhan, S., and Klouček, P. (2020). The effct of infrared drying on color, projected area, drying time, and total phenolic content of rose (rose electron) petals. Plants 9:236. doi: $10.3390 /$ plants9020236

Shchitov, S., Reshetnik, E., Evdokimov, V., Perepelkina, L. P., Krivuca, Z., Samarina, Y., et al. (2019). Using infrared radiation in preparation of feed for farm livestock. Indonesian J. Electr. Eng. Comput. Sci. 15, 148-154. doi: 10.11591/ijeecs.v15.i1.pp,148-154

Takamasa, T. (2017). Persimmon Producción Method Dryed Sin Generación Mode Y Oxidación. Japón Patente $n^{\circ}$ JP2017147987.

Treybal, R. (1986). Operaciones de transferencia de masa. RI: Mc Graw Hill.

Valiente, B. A., and Tlacatzin, S. R. (1991). Matter and Energy Balance Problems. México: Alhambra Mexicana S.A. DE C.V.

Vega-Gálvez, A., Poblete, J., Quispe-Fuentes, I., Uribe, E., Bilbao-Sainz, C., and Pastén, A. (2019). Chemical and bioactive characterization of papaya (Vasconcellea pubescens) under different drying technologies: evaluation of antioxidant and antidiabetic potential. J. Food Measure. Characterization 13, 1980-1990. doi: 10.1007/s11694-019-00117-4

Wang, Q. L. (2019). Quality evaluation and drying kinetics of shitake mushrooms dried by hot air, infrared and intermittent microwave-assisted drying methods. Food Sci. Technol. 107, 236-242. doi: 10.1016/j.lwt.2019. 03.020

Wang, X., Feng, Y., Zhou, C., Sun, Y., Wu, B., Yagoub, A., et al. (2019). Effect of vacuum and ethanol pretreatment on infrared-hot air drying of scallion (Allium fistulosum). Food Chem. 295, 432-440. doi: 10.1016/j.foodchem.2019. 05.145

Warren Mcabe, J. S. (1991). Unit operations in Chemical Engineering. New York, NY: Mc Graw Hill.

Wicherski, J. (2018). Device and method of dehydration of biological products. Poland Patent No. US20180168203

$\mathrm{Wu}, \mathrm{X}$.-f., Zhang, M., and Li, Z. (2019). Influence of infrared drying on the drying kinetics, bioactive compounds, and flavor of Cordyceps militaris. LWT Food Sci. Technol. 111, 790-798. doi: 10.1016/j.lwt.2019.05.108

Wu, X.-F., and Zhang, M. B. (2019). A novel infrared freeze-drying (IRFD) technology to lower the energy consumption and keep the quality of Cordyceps militaris. Innov. Food Sci. Emerg. Technol. 54, 34-42. doi: 10.1016/j.ifset,.2019.03.003

Yan, J., Wu, L., Qiao, Z., Cai, W., and Ma, H. (2019). Effect of different drying methods on the product quality and bioactive polysaccharides of bitter gourd (Momordica charantia L.) slices. Food Chem. 271, 588-596. doi: 10.1016/j.foodchem.2018.08.012

Yao, L., Fan, L., and Duan, Z. (2019). Effect of different pretreatments followed by hot-air and far-infrared drying on the bioactive compounds, physicochemical 
property, and microstructure of mango slices. Food Chem. 305:125477. doi: 10.1016/j.foodchem.2019.125477

Yu, Q., Li, J., and Fan, L. (2019). Effect of drying methods on the microstructure, bioactivity substances, and antityrosinase activity of asparagus stems. J. Agri. Food Chem. 67, 1537-1545. doi: 10.1021/acs.jafc.8b05993

Zartha, S. J. W., and Palacio, P. J. C. (2011). Agricultural Operations and Processes Medellín: Editorial UPB.

Zeng, Y., Liu, Y., Zhang, J., Xi, H., and Duan, X. (2019). Effects of far-infrared radiation temperature on drying characteristics, water status, microstructure, and quality of kiwifruit slices. J. Food Measure. Characterization 13, 3086-3096. doi: 10.1007/s11694-01900231-3

Zhao, Y., Bi, J., Yi, J., Jin, X., Wu, X., and Zhou, M. (2019). Evaluation of sensory, textural, and nutritional attributes of shiitake mushrooms (Lentinula edodes) as prepared by five types of drying methods. J. Foods Process Eng. 42:e13029. doi: $10.1111 /$ jfpe. 13029
Zhou, M., li, C., Bi, J., Jin, X., and Lyu, J. (2019). Towards understanding the enhancement of moisture diffusion during intermediate-infrared drying of peach pomace based on the glass transition theory. Innov. Food Sci. Emerg. Technol. 54, 143-151. doi: 10.1016/j.ifset.2019.04.003

Conflict of Interest: The authors declare that the research was conducted in the absence of any commercial or financial relationships that could be construed as a potential conflict of interest.

Copyright (c) 2021 Zartha Sossa, Orozco, García Murillo, Peña Osorio and Sánchez Suarez. This is an open-access article distributed under the terms of the Creative Commons Attribution License (CC BY). The use, distribution or reproduction in other forums is permitted, provided the original author(s) and the copyright owner(s) are credited and that the original publication in this journal is cited, in accordance with accepted academic practice. No use, distribution or reproduction is permitted which does not comply with these terms. 